\title{
Feasibility Technique of Low-passage In Vitro Drug Sensitivity Testing of Malignant Pleural Effusion from Advanced-stage Non-small Cell Lung Cancer for Prediction of Clinical Outcome
}

\author{
CHANIDA VINAYANUWATTIKUN ${ }^{1 *}$, ORNJIRA PRAKHONGCHEEP ${ }^{2,3^{*}}$, \\ SUCHARAT TUNGSUKRUTHAI ${ }^{2,3}$, KORRAKOD PETSRI $^{2,3}$, PRAPASSORN THIRASASTR ${ }^{1}$, \\ NOPHOL LEELAYUWATANAKUL ${ }^{4}$ and PITHI CHANVORACHOTE ${ }^{2,3}$ \\ ${ }^{1}$ Division of Medical Oncology, Department of Medicine, Faculty of Medicine, \\ Chulalongkorn University, Bangkok, Thailand; \\ ${ }^{2}$ Cell-Based Drug and Health Product Development Research Unit, \\ Faculty of Pharmaceutical Sciences, Chulalongkorn University, Bangkok, Thailand; \\ ${ }^{3}$ Department of Pharmacology and Physiology, Faculty of Pharmaceutical Sciences, \\ Chulalongkorn University, Bangkok, Thailand; \\ ${ }^{4}$ Division of Pulmonary and Critical Care Medicine, Department of Medicine, \\ Faculty of Medicine, Chulalongkorn University, Bangkok, Thailand
}

\begin{abstract}
Background/Aim: Individualized proper chemotherapy using in vitro drug sensitivity testing has been proposed as a novel therapeutic modality and shown to have better efficacy than empiric chemotherapy. However, issues around establishing a patient-derived cell culture or xenograft, the timing of the testing obtained, and the validity of testing represent major limitations to translating the use of such a technique to clinical practice. Patients and Methods: In this study, we assessed the feasibility of an in vitro drug sensitivity technique for testing malignant pleural effusion from advancedstage non-small cell lung cancer. Results: Our technique was able to produce a turnaround time for in vitro drug sensitivity testing of less than 1 week, with a success rate of more than $90 \%$ of cases. Correlated with the individual clinical outcome, using the area under the dose response curve (AUC) could define the level of in vitro drug sensitivity as: responsive (AUC>0.25), intermediate response $(0.1 \leq A U C \leq 0.25)$, or
\end{abstract}

*These Authors contributed equally to this study.

Correspondence to: Dr. Pithi Chanvorachote, Associated Professor, Department of Pharmacology and Physiology, Faculty of Pharmaceutical Sciences, and Cell-based Drug and Health Product Development Research Unit, Chulalongkorn University, Phatumwan, Bangkok 10330, Thailand. Tel: +662 2188344, Fax: +662 2188340, e-mail: pithi.c@chula.ac.th

Key Words: In vitro drug sensitivity testing, precision medicine, malignant pleural effusion, advanced stage non-small cell lung cancer. resistance $(A U C<0.1)$. Conclusion: Data obtained from this method of drug testing were correlated with the clinical outcome. The present drug sensitivity evaluation may benefit the development of individual precision chemotherapy.

The response rate from standard platinum-doublet chemotherapy for advanced non-small cell lung cancer (NSCLC) ranges from $25-30 \%$ with a 1-year survival rate of up to $30 \%$ $(1,2)$. With the advancement of molecular biomarkers and targeted therapy, the survival of advanced lung cancer patients with sensitizing mutation who receive matched targeted therapy can increase up to 30-36 months (3). It is potentially noteworthy that defining optimized therapeutic agents for individual patients could be beneficial in terms of treatment efficiency, economical concerns, and avoidance of unnecessary toxicity $(4,5)$. The in vitro drug sensitivity concept has been explored with both patient-derived xenografts (PDXs) and as a primary cell culture model. It was claimed that the PDX model is expensive and has a low engraftment rate, and may not give results back in a timely manner to instruct therapeutic decisions. Further, it might not represent the real clinical response due to the lack of interaction between human stromal cells and the immune system (6). Patient-derived organoids (PDOs) is a model providing another option for drug sensitivity testing but work is still in progress in this area. Among the several in vitro drug sensitivity assays that have been developed, the methyl thiazol-diphenyl-tetrazolium bromide (MTT) assay, based on the measurement of mitochondrial enzyme activity, is the most widely used technique due to its simplicity, sensitivity, and reliability (7). This technique could 
define the viability of cancer cells after culture with anticancer agents. However, the concentration of anticancer agents and how to define sensitivity or resistance in the clinic have yet to be concluded. Furthermore, the super-therapeutic concentration of anticancer agents that have been used to define the threshold sensitivity might not represent a good clinical response.

Flourishing patient-derived cell culture and passage variation are two other issues of concern. In particular, patient-derived cell cultures can be difficult to sustain, which is a major limitation with in vitro drug sensitivity testing. Furthermore, advancements in multiple passages may lead to selection of undesired cell subpopulations and a change in the pattern of genomic characteristic and even cancer phenotypes (8). Herein, we hypothesize that testing very early passage or patient-derived primary cells directly from a patient without propagation might be an efficient method to define drug sensitivity. Consequently, the present study was conducted to define the proper in vitro drug sensitivity testing of malignant pleural effusion from advanced stage non-small cell lung cancer, and the results were assessed for clinical correlation and potential clinical application.

\section{Patients and Methods}

Study population. A prospective cohort of 11 recurrent or advancedstage non-small cell lung patients with malignant pleural effusion who had been diagnosed at the King Chulalongkorn Memorial Hospital and treated with either standard platinum-doublet chemotherapy or secondline chemotherapy, specifically with docetaxel or pemetrexed, were enrolled in the study. In vitro drug sensitivity was tested for 5 agents, namely gemcitabine, pemetrexed, docetaxel, vinorelbine, and erlotinib, which were obtained from Sigma-Aldrich (St. Louis, MO, USA). We chose these agents to correlate with the patients' history of prior or potential further subsequent chemotherapy. The treatment decision, objective response rate, and progression-free survival according to treatment were determined by the physicians as standard practice through the patients' medical records. The response rate was defined as the maximum response of the treatment, referring to the RECIST v1.1 criterion (9). In brief, complete response (CR) referred to the disappearance of the target and non-target lesion, partial response (PR) referred to a decrease in the target lesion of more than $30 \%$, progressive disease (PD) referred to an increase in the target lesions of at least $20 \%$ or the development of a new lesion, and stable disease (SD) referred to a lesion that was not PD or PR. Progression-free survival of a particular treatment was defined as the duration since the start of such treatment to progression of the disease. The study was approved by the Ethics Committee of the Faculty of Medicine, Chulalongkorn University, Bangkok, Thailand (IRB 365/62). Written informed consent was obtained from all the participants.

Protocol for cancer cell preparation from malignant pleural effusion. The study aimed to determine in vitro drug sensitivity in isolated patient-derived primary lung cancer cells directly without cultivation. Primary cancer cells were obtained from pleural effusion (500-1,000 ml) by thoracentesis and collected aseptically in heparinized. Samples were centrifuged at $300 \mathrm{~g}$ for $10 \mathrm{~min}$, at $4^{\circ} \mathrm{C}$, and cell pellet was resuspended in $10 \%$ FCS-RPMI
Table I. Concentration of chemotherapeutic agents in every fold (0.54) that had been conducted in the in vitro testing for chemotherapeutic sensitivity. One-fold chemical concentration refers to the average plasma concentration of the recommended dose for lung cancer treatment.

\begin{tabular}{lcccc}
\hline Chemotherapeutic agent & \multicolumn{4}{c}{ Concentration in each fold $(\mu \mathrm{g} / \mathrm{ml})$} \\
\cline { 2 - 5 } & 0.5 & 1 & 2 & 4 \\
\hline Gemcitabine & 2.70 & 5.40 & 10.80 & 21.60 \\
Pemetrexed & 1.35 & 2.70 & 5.40 & 10.80 \\
Docetaxel & 0.27 & 0.54 & 1.08 & 2.16 \\
Vinorelbine & 0.08 & 0.16 & 0.32 & 0.64 \\
Erlotinib & 0.07 & 0.14 & 0.27 & 0.54 \\
\hline
\end{tabular}

(Invitrogen). Viability was determined by the Trypan Blue exclusion dye. After a harvesting and 2 rounds of washing, the cells were subjected to drug sensitivity testing.

In vitro drug sensitivity testing (DST). For the cytotoxicity assay, approximately $0.8-1.5 \times 10^{4}$ living cells determined by the Trypan Blue exclusion assay were seeded in 1 well of 96-well plates. The cultures were then incubated at $37^{\circ} \mathrm{C}$ in humidified atmosphere containing $5 \%$ $\mathrm{CO}_{2}$. After cells adhering, cells were immediately treated with various concentrations of drugs for $24 \mathrm{~h}$ in at least triplicate fashion. The chemotherapeutic concentrations were calculated based on recommended therapeutic dose and plasma concentration of each drug (10) following by justified using human conversion factor and human blood volume (11). The cancer cells were treated with various concentrations of the drug form 0.5-4-fold. The calculated concentrations of each drug are presented in Table I. Cells were incubated with $500 \mu \mathrm{g} / \mathrm{ml}$ of MTT at $37^{\circ} \mathrm{C}$ for $4 \mathrm{~h}$ and the formazan crystals were solubilized in $100 \mu \mathrm{l}$ DMSO and measured at wavelength $570 \mathrm{~nm}$ with microplate reader (Anthros, Durham, NC, USA). Relative cell viability was calculated by dividing the absorbance of the treated cells by that of the control cells. Untreated cells were visualized randomly using light microscope (Olympus IX5, Tokyo, Japan).

Definition of in vitro drug sensitivity testing results. We calculated AUC (Area under the dose response curve); represent response area (1- vitality), which could capture the efficacy and potency of drug to represent particular drug sensitivity better than either $\mathrm{IC}_{50}$ (Inhibitory concentration of compound that reaches 50\% reduction in cell viability) or $\mathrm{EC}_{50}$ (Inhibitory concentration of compound that reach 50\% maximum reduction in cell viability) (12). High AUC implying high sensitivity to the drug. In this study, we defined drug sensitivity by correlated with clinical outcome; resistance referred for $\mathrm{AUC}<0.10$, Intermediate response referred for AUC range (0.010.25 ) and responsive referred for $A U C>0.25$. The AUC calculation was done using PharmacoGx R package (13).

\section{Results}

Individual in vitro drug sensitivity testing and clinical correlation. An in vitro drug sensitivity assay for five agents was successfully performed with 11 pleural effusions (>90\%), with data obtained within 1 week from the time of 
Table II. Clinical characteristic of advanced/recurrent non-small cell lung cancer patients retrieved for malignant pleural effusion collection (MPE) and conduct low-passage cell culture in vitro drug sensitivity testing. Time point of specimen collection (gray arrow) is shown related to the provided treatment. Outcome of treatment is represented by the maximal (max) responses, comprising PR (partial response), SD (stable disease), PD (progression of disease) by the provided physician and progression-free survival (PFS).

\begin{tabular}{|c|c|c|c|c|c|}
\hline $\begin{array}{l}\text { Study } \\
\text { ID }\end{array}$ & Compound & AUC & Prediction & $\begin{array}{l}\text { MPE time point } \\
\text { collection }\end{array}$ & Information (treatment; Max response; PFS) \\
\hline PM1 & $\begin{array}{l}\text { Gemcitabine } \\
\text { Pemetrexed } \\
\text { Docetaxel } \\
\text { Vinorelbine }\end{array}$ & $\begin{array}{l}0.24 \\
0.12 \\
0.09 \\
0.33\end{array}$ & $\begin{array}{l}\text { Intermediate } \\
\text { Intermediate } \\
\text { Resistance } \\
\text { Responsive }\end{array}$ & $\mathbf{1 L}_{2 \mathrm{~L}} \mathbf{2 L}_{3 \mathrm{~L}} \boldsymbol{}_{4 \mathrm{~L}}$ & $\begin{array}{l}\text { 1L Erlotinib; PR; 125wk } \\
\text { 2L Carboplatin/Pemetrexed; PR; 33wk } \\
\text { 3L Docetaxel; PD; 8wk } \\
\text { 4L Gemcitabine; SD; } 12 \text { wk }\end{array}$ \\
\hline PM4 & $\begin{array}{l}\text { Gemcitabine } \\
\text { Pemetrexed } \\
\text { Docetaxel } \\
\text { Vinorelbine }\end{array}$ & $\begin{array}{c}0 \\
0 \\
0.31 \\
0.37\end{array}$ & $\begin{array}{l}\text { Resistance } \\
\text { Resistance } \\
\text { Responsive } \\
\text { Responsive }\end{array}$ & 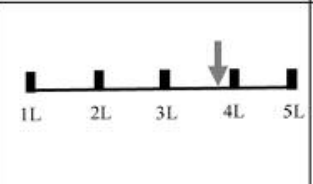 & $\begin{array}{l}\text { 1L Carboplatin/gemcitabine; PR; 37wk } \\
\text { 2L Docetaxel; SD; } 51 w k \\
\text { 3L Erlotinib; PR; 89wk } \\
\text { 4L Pemetrexed; PD; 2wk } \\
\text { 5L Osimertinib; PR; } 22 \text { wk and ongoing }\end{array}$ \\
\hline ELC07 & $\begin{array}{l}\text { Gemcitabine } \\
\text { Pemetrexed } \\
\text { Docetaxel } \\
\text { Vinorelbine }\end{array}$ & $\begin{array}{c}0 \\
0 \\
0 \\
0.25\end{array}$ & $\begin{array}{l}\text { Resistance } \\
\text { Resistance } \\
\text { Resistance } \\
\text { Responsive }\end{array}$ & $\underbrace{}_{11 .} \underbrace{}_{3 \mathrm{~L}}$ & $\begin{array}{l}\text { 1L Carboplatin/Pemetrexed; PD; 10wk } \\
\text { 2L Docetaxel; PR; 25wk } \\
\text { 3L Vinorelbine; intolerate }\end{array}$ \\
\hline ELC08 & $\begin{array}{l}\text { Gemcitabine } \\
\text { Pemetrexed } \\
\text { Docetaxel } \\
\text { Vinorelbine }\end{array}$ & $\begin{array}{c}0 \\
0 \\
0 \\
0.008\end{array}$ & $\begin{array}{l}\text { Resistance } \\
\text { Resistance } \\
\text { Resistance } \\
\text { Resistance }\end{array}$ & 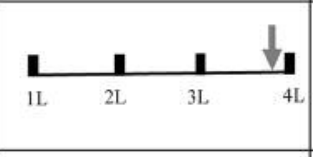 & $\begin{array}{l}\text { 1L Carboplatin/Pemetrexed; SD; 27wk } \\
\text { 2L Docetaxel; PD; 10wk } \\
\text { 3L Erlotinib; SD; 17wk } \\
\text { 4L Atezolizumab; NA }\end{array}$ \\
\hline ELC10 & $\begin{array}{l}\text { Gemcitabine } \\
\text { Pemetrexed } \\
\text { Docetaxel } \\
\text { Vinorelbine }\end{array}$ & $\begin{array}{c}0 \\
0 \\
0 \\
0.16\end{array}$ & $\begin{array}{l}\text { Resistance } \\
\text { Resistance } \\
\text { Resistance } \\
\text { Intermediate }\end{array}$ & $\underbrace{}_{11 .}$ & $\begin{array}{l}\text { 1L Gefitinib; SD; 20wk } \\
\text { 2L Carboplatin/Gemcitabine; PR; 11wk } \\
\text { 3L Pemetrexed; intolerate }\end{array}$ \\
\hline ELC23 & $\begin{array}{l}\text { Gemcitabine } \\
\text { Pemetrexed } \\
\text { Docetaxel } \\
\text { Vinorelbine } \\
\text { Erlotinib }\end{array}$ & $\begin{array}{c}0.01 \\
0 \\
0.09 \\
0.08 \\
0\end{array}$ & $\begin{array}{l}\text { Resistance } \\
\text { Resistance } \\
\text { Resistance } \\
\text { Resistance } \\
\text { Resistance }\end{array}$ & $\underset{1 L}{1 L}$ & 1L Carboplatin/Pemetrexed; PR; 23 wk \\
\hline ELC17 & $\begin{array}{l}\text { Gemcitabine } \\
\text { Pemetrexed } \\
\text { Docetaxel } \\
\text { Vinorelbine }\end{array}$ & $\begin{array}{c}0 \\
0 \\
0.17 \\
0.12\end{array}$ & $\begin{array}{l}\text { Resistance } \\
\text { Resistance } \\
\text { Intermediate } \\
\text { Intermediate }\end{array}$ & $\underset{\text { II. }}{\mathbf{P D}}$ & 1L Carboplatin/Paclitaxel/Avastin; PD; 11 wk \\
\hline ELC22 & $\begin{array}{l}\text { Gemcitabine } \\
\text { Pemetrexed } \\
\text { Docetaxel } \\
\text { Vinorelbine } \\
\text { Erlotinib }\end{array}$ & $\begin{array}{c}0 \\
0 \\
0.05 \\
0 \\
0 \\
\end{array}$ & $\begin{array}{l}\text { Resistance } \\
\text { Resistance } \\
\text { Resistance } \\
\text { Resistance } \\
\text { Resistance }\end{array}$ & $\underset{11}{\frac{1}{2}}$ & $\begin{array}{l}\text { 1L Carboplatin/Paclitaxel; PD; } 6 \text { wk } \\
\text { 2L Atezolizumab; ongoing }\end{array}$ \\
\hline ELC27 & $\begin{array}{l}\text { Gemcitabine } \\
\text { Pemetrexed } \\
\text { Docetaxel } \\
\text { Vinorelbine } \\
\text { Erlotinib }\end{array}$ & $\begin{array}{c}0 \\
0 \\
0.21 \\
0 \\
0.05\end{array}$ & $\begin{array}{l}\text { Resistance } \\
\text { Resistance } \\
\text { Intermediate } \\
\text { Resistance } \\
\text { Resistance }\end{array}$ & $\frac{\downarrow}{\text { 2I. }} \frac{1}{\mathrm{PD}}$ & $\begin{array}{l}\text { 1L Gefitinib; SD, } 32 \mathrm{wk} \\
\text { 2L Carboplatin/paclitaxel; PD; } 11 \mathrm{wk}\end{array}$ \\
\hline ELC30 & $\begin{array}{l}\text { Gemcitabine } \\
\text { Pemetrexed } \\
\text { Docetaxel } \\
\text { Vinorelbine } \\
\text { Erlotinib }\end{array}$ & $\begin{array}{l}0.01 \\
0.01 \\
0.03 \\
0.18 \\
0.21\end{array}$ & $\begin{array}{l}\text { Resistance } \\
\text { Resistance } \\
\text { Resistance } \\
\text { Intermediate } \\
\text { Intermediate }\end{array}$ & $\underset{\text { II. }}{\text { 2I. }}$ & $\begin{array}{l}\text { 1L Carboplatin/gemcitabine; SD; } 44 \text { wk } \\
\text { 2L Docetaxel; PR; } 35 \text { wk } \\
\text { 3L Carboplatin/paclitaxel; } 2 \text { cycle \& ongoing }\end{array}$ \\
\hline ELC31 & $\begin{array}{l}\text { Gemcitabine } \\
\text { Pemetrexed } \\
\text { Docetaxel } \\
\text { Vinorelbine } \\
\text { Erlotinib }\end{array}$ & $\begin{array}{c}0 \\
0 \\
0 \\
0.15 \\
0 \\
\end{array}$ & $\begin{array}{l}\text { Resistance } \\
\text { Resistance } \\
\text { Resistance } \\
\text { Intermediate } \\
\text { Resistance }\end{array}$ & & $\begin{array}{l}\text { 1L Carboplatin/paclitaxel; SD; } 64 \mathrm{wk} \\
\text { 2L Docetaxel; PD; } 15 \mathrm{wk}\end{array}$ \\
\hline
\end{tabular}

PFS: Progression-free survival defined as time from start treatment to progression of that compound; Max: maximal response of treatment (CR, PR, SD, PD) was assessed by provided physician after 2-3 cycle of chemotherapy by using RECIST v.1.1. 

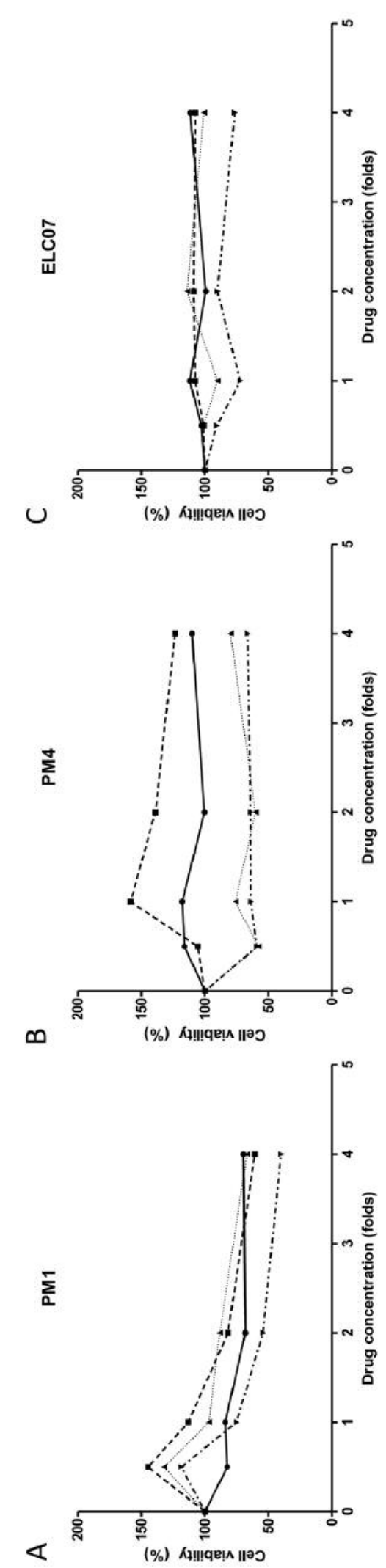
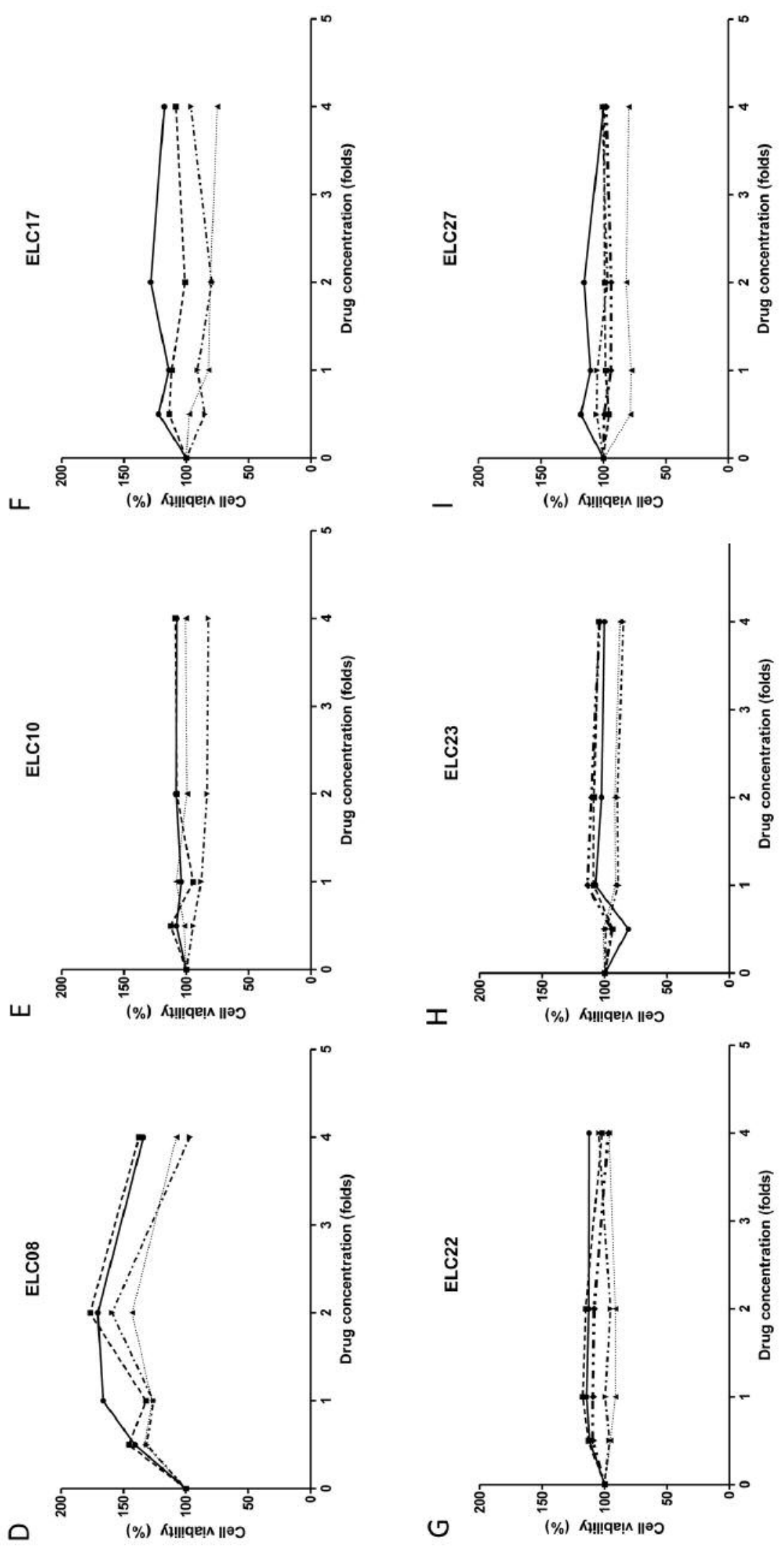

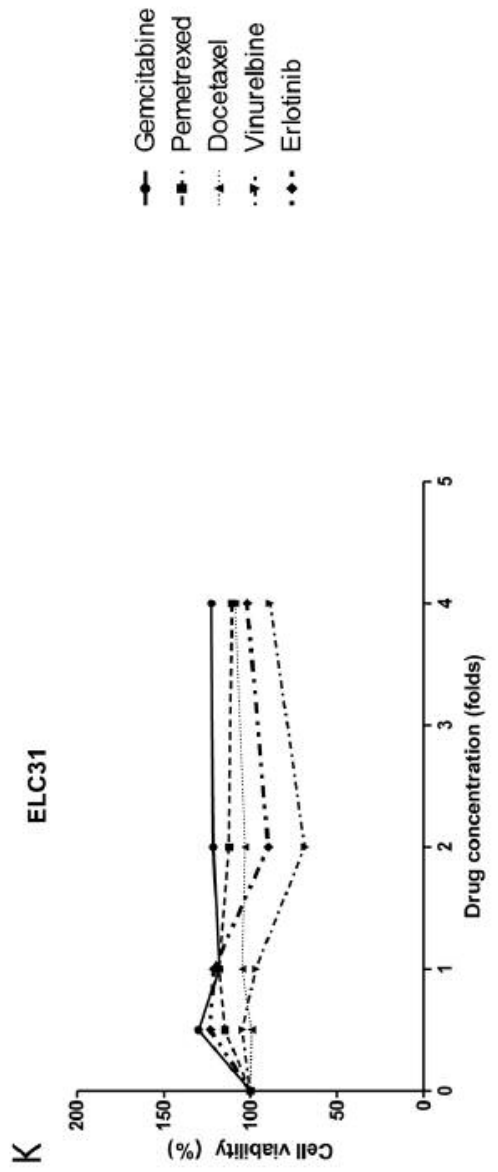

collection. However, in only 3 cases did the results from the in vitro drug sensitivity returned to the provided physician influence their decision making. The actual dose response curve is shown in Figure 1. Table II presents information on the patients according to the treatment and the condition of the 11 successfully performed in vitro drug sensitivity patients, and further, brief outlines of each case are given below.

Case PM1. A 64-year-old male adenocarcinoma patient who had EGFR exon 19 deletion. He had quite long-term disease control from $2 \mathrm{~L}$ (second-line) platinum-double chemotherapy (carboplatin/paclitaxel). However, at the time of disease progression after 3L (third-line) docetaxel, pleural fluid had been collected and indicated an in vitro sensitivity pattern of resistance to docetaxel (AUC $=0.09$ ). Subsequent treatment in this patient involved gemcitabine. In vitro drug sensitivity showed intermediate activity on gemcitabine (AUC=0.24). He had a stable disease from this agent and continued for 5 cycles before the disease became uncontrolled.

Case PM4. A 69-year-old female who a had very long disease control after completing 6 cycles (3-week intervals per cycle) of $2 \mathrm{~L}$ docetaxel for up to 51 weeks. Her clinical response was correlated with an in vitro modest response to docetaxel (AUC=0.31). Molecular testing at the time of disease progression on $3 \mathrm{~L}$ erlotinib revealed EGFR L858R T790M, but she could not afford osimertinib at that time. Consequently, $4 \mathrm{~L}$ pemetrexed was provided without a clinical response consistent with in vitro sensitivity, which indicated a resistance to pemetrexed $(\mathrm{AUC}=0)$.

Case ELC07. A 65-year-old female for whom pleural effusion had been collected after progression on docetaxel and revealed a modest response only to vinorelbine (AUC=0.25). Even though vinorelbine is not the standard chemotherapy regimen after docetaxel failure, the physician decided to use this agent according to the in vitro sensitivity testing results. However, due to poor performance status, this patient could not tolerate chemotherapy. Only a 2-week interval of vinorelbine $25 \mathrm{mg} / \mathrm{m}^{2}$ was provided. She then had a urinary tract infection, which interrupted treatment, before progression of the disease.

Case ELC08. An 82-year-old male for whom pleural effusion had been collected after 3L erlotinib. In vitro drug sensitivity testing revealed pan-resistance to all potential chemotherapy. The patient had received subsequent immunotherapy per standard practice. The patient's symptoms worsened after 1 cycle of treatment and he expired 2 weeks after treatment. 
Case ELC10. A 71-year-old female who had progression after the 4 th cycle of $2 \mathrm{~L}$ carboplatin and gemcitabine. Pleural effusion had been collected after the 1 st cycle of $3 \mathrm{~L}$ pemetrexed. She had febrile neutropenia and her worsening condition prohibited subsequent chemotherapy. Medical pleurodesis was provided to control her symptoms. However, in vitro drug sensitivity revealed resistance to pemetrexed.

Case ELC23. An 83-year-old male who had received firstline chemotherapy; carboplatin/pemetrexed for 4 cycles, and maintenance with pemetrexed for 2 cycles, before stopping due to progression of the disease. Radiotherapy was planned to control the symptoms of non-massive hemoptysis, but interrupted due to acute myocardial infarction, but he expired in that admission. Even though this patient did not receive subsequent chemotherapy, in vitro drug sensitivity revealed resistance to pemetrexed, consistent with the clinical progression upon treatment.

Case ELC17. A 73-year-old female who had disease progression after 4 cycles of first-line carboplatin/paclitaxel and bevacizumab. Due to poor performance, this patient could not receive subsequent chemotherapy. Intermittent thoracocentesis and the release of pleural effusion was provided. The patient's in vitro drug sensitivity profile revealed an intermediate response to docetaxel and vinorelbine. Furthermore, it also showed a resistance pattern to pemetrexed and gemcitabine.

Case ELC22. A 63-year-old male adenocarcinoma patient with wild-type $E G F R$ testing had disease progression from 3 cycles of first-line carboplatin/paclitaxel. Pleural effusion was collected at the time of disease progression. This patient had a poor performance status, which limited further chemotherapy. Atezolizumab, an anti-PD-L1 antibody, was considered and treatment is currently ongoing. According to molecular testing of wild-type EGFR, the in vitro drug sensitivity profile revealed a resistance to erlotinib.

Case ELC27. A 75-year-old female who had long disease control from 1L gefitinib but no response from $2 \mathrm{~L}$ carboplatin/paclitaxel. The pleural effusion had been collected afterward. In vitro drug sensitivity revealed only an intermediate response to docetaxel chemotherapy, but she refused to receive further chemotherapy.

Case ELC30. A 41-year-old female who had quite a long duration of disease control after 4 cycles of carboplatin/gemcitabine and 6 cycles of docetaxel. Despite molecular testing revealing EGFR exon 19 mutation, she could not afford targeted therapy nor the non-national drug list pemetrexed. The physician considered retreatment with platinum-doublet chemotherapy, with carboplatin/paclitaxel.
According to her sensitivity EGFR mutation pattern, in vitro sensitivity testing revealed an intermediate response to erlotinib (AUC=0.21).

Case ELC31. A 67-year-old female who had disease control after 6 cycles of first-line chemotherapy, with carboplatin and paclitaxel. According to oligometastasis, this patient had consolidative radiation to prolong overall disease controlled. Subsequent chemotherapy, with docetaxel, was provided with a complication of grade IV neutropenia after the 1st cycle of treatment. According to treatment interruption, medical pleurodesis was provided with pleural fluid collection. Subsequent imaging revealed progression of the disease consistent with the in vitro sensitivity testing (AUC for docetaxel $=0$ ).

\section{Discussion}

The efficacy of individualized chemotherapy selected by in vitro drug sensitivity testing has been shown to offer better efficacy than empiric therapy $(14,15)$. Several techniques for in vitro drug sensitivity testing have been used. However, the significant progression of in vitro drug sensitivity testing is still limited and it cannot yet be implemented in routine clinical usage. The feasibility to maintain patient-derived in vitro cell cultures, the timing of obtaining the test results, and the validity of interpreting the results from such in vitro drug sensitivity testing are major issues in the field. In this study, we demonstrated a feasible technique involving a lowpassage cell culture and defined an optimal in vitro drug sensitivity dosage (range $=1-4$ fold) related to the standard therapeutic dosage for that disease. The results of the in vitro drug sensitivity were obtained within 1 week and could give a yield of up to $90 \%$. Incorporated with the clinical response, we could define a cut-off in vitro drug sensitivity level as a responsive, intermediate, or resistance pattern. The results from the in vitro sensitivity pattern influenced the clinical judgment of the provided physician in terms of the compound that should be used for individual patients. The main purpose of incorporating in vitro sensitivity testing in recurrent disease is not to risk patients receiving an ineffective treatment, especially frail elderly patients, and it could probably affect the retreatment strategy by showing the response from a prior treatment compound. Furthermore, the use of the MTT technique to define a growth inhibition of $50 \%$ (IC50) has been widely used to represent drug sensitivity in large-scale pharmacogenomics resources (16). To obtain such a value, a super-therapeutic concentration of anticancer agents is needed particular for resistance clones, but is not needed in our protocol. We propose using the area under the dose response curve (AUC) to represent the entire cell response curve as a measure of sensitivity to provide adequate information for decision-making about whether a 
patient has sensitivity or resistance to a particular chemotherapy

Early-passage patient-derived cell culture is defined by various definitions. An inconsistent genomic landscape from patient-derived cell culture and the patient-derived xenograft model have been reported in cases with more than 10 passages (17). These inconsistent findings have also been reported in various patient-derived cancer cell cultures between early (lower than p5) and later passage (greater than p10) cases (18). Nevertheless, an earlier passage (less than p10) patient-derived cell culture retained particular copy number variations, gene mutation, and miRNA expression compared to primary breast cancers (19). A low-passage cell culture could diminish the in vitro influences that might impact the phenotype of the cancer cells to represent the real clinical situation. Moreover, a short culture assay will minimize the variable effects of cell proliferation and cell death over the assay period (9). We herein proposed the feasibility of an in vitro drug sensitivity technique that could systematically support investigations of the biology of various cancer types. This assay may have potential clinical applications for predictive chemotherapy selection. Further exploration with treatment-naïve cancer patients and model prediction might be warranted.

\section{Funding}

This project was financially supported by the Chulalongkorn Academic Advancement under its 2nd Century Project to CV. Thanks also to the Ratchadaphiseksomphot Fund , Chulalongkorn University, for awarding a Postdoctoral Fellowship to OP.

\section{Conflicts of Interest}

The Authors have no conflicts of interest to declare.

\section{Authors' Contributions}

OP: Methodology, investigation, data curation, writing, including review and editing; ST: Investigation; KP: Investigation; NL: Participant recruitment, methodology; PT: Investigation; CV: Methodology, investigation, conceptualization, funding acquisition, writing the original draft, writing-review and editing; PC: Methodology, investigation, funding acquisition, writing-review and editing.

\section{Acknowledgements}

The Authors would like to thank the nursing staff at Pulmonary and Critical Care Medicine; Mrs. Daorung Silachamroon, who provided participant information and assisted specimen collection as laboratory technician of the Medicine Oncology Division; and Ms. Suleerut Prasert, also of the Medical Oncology Division, for processing the pleural effusion collections from the advanced nonsmall cell lung cancer patients.

\section{References}

1 NSCLC Meta-Analyses Collaborative Group: Chemotherapy in addition to supportive care improves survival in advanced nonsmall-cell lung cancer: a systematic review and meta-analysis of individual patient data from 16 randomized controlled trials. J Clin Oncol 26(28): 4617-4625, 2008. PMID: 18678835. DOI: 10.1200/JCO.2008.17.7162

2 Linardou H, Kotoula V, Kouvatseas G, Mountzios G, Karavasilis V, Samantas E, Kalogera-Fountzila A, Televantou D, Papadopoulou K, Mavropoulou X, Daskalaki E, Zaramboukas T, Efstratiou I, Lampaki S, Rallis G, Res E, Syrigos KN, Kosmidis PA, Pectasides D, Fountzilas G: Genotyping KRAS and EGFR mutations in Greek patients with non-small-cell lung cancer: Incidence, significance and implications for treatment. Cancer Genomics Proteomics 16(6): 531-541, 2019. PMID: 31659106. DOI: $10.21873 / \operatorname{cgp} .20155$

3 Kris MG, Johnson BE, Berry LD, Kwiatkowski DJ, Iafrate AJ, Wistuba II, Marileila V-G, Franklin WA, Aronson SL, Su PF, Shyr Y, Camidge DR, Sequist LV, Glisson BS, Khuri FR, Garon EB, Pao W, Rudin C, Schiller J, Haura EB, Socinski M, Shirai K, Chen H, Giaccone G, Ladanyi M, Kugler K, Minna JD and Bunn PA: Using multiplexed assays of oncogenic drivers in lung cancers to select targeted drugs. JAMA 311(19): 1998-2006, 2014. PMID: 24846037. DOI: 10.1001/jama.2014.3741

4 Fujita T, Kuroki T, Hayama N, Shiraishi Y, Amano H, Nakamura M, Hirano S, Tabeta $\mathrm{H}$ and Nakamura S: Pemetrexed plus platinum for patients with advanced non-small cell lung cancer and interstitial lung disease. In Vivo 33(6): 2059-2064, 2019. PMID: 31662538. DOI: 10.21873/invivo.11704

5 Harada D, Takata K, Mori S, Kozuki T, Takechi Y, Moriki S, Asakura Y, Ohno T and Nogami N: Previous immune checkpoint inhibitor treatment to increase the efficacy of docetaxel and ramucirumab combination chemotherapy. Anticancer Res 39(9): 4987-4993, 2019. PMID: 31519605. DOI: 10.21873/anticanres. 13688

6 Lai Y, Wei X, Lin S, Qin L, Cheng L and Li P: Current status and perspectives of patient-derived xenograft models in cancer research. J Hematol Oncol 10(1): 106, 2017. PMID: 28499452. DOI: $10.1186 / \mathrm{s} 13045-017-0470-7$

7 Hatok J, Babusikova E, Matakova T, Mistuna D, Dobrota D and Racay P: In vitro assays for the evaluation of drug resistance in tumor cells. Clin Exp Med 9(1): 1-7, 2009. PMID: 18818983. DOI: $10.1007 / \mathrm{s} 10238-008-0011-3$

8 Ben-David U, Beroukhim R and Golub TR: Genomic evolution of cancer models: perils and opportunities. Nat Rev Cancer 19(2): 97-109, 2019. PMID: 30578414. DOI: 10.1038/s41568018-0095-3

9 Eisenhauer EA, Therasse P, Bogaerts J, Schwartz LH, Sargent D, Ford R, Dancey J, Arbuck S, Gwyther S, Mooney M, Rubinstein L, Shankar L, Dodd L, Kaplan R, Lacombe D and Verweij J: New response evaluation criteria in solid tumours: revised RECIST guideline (version 1.1). Eur J Cancer 45(2): 228-47, 2009. PMID: 19097774. DOI: 10.1016/j.ejca.2008.10.026

10 Chu E and DeVita VT: Physicians' Cancer Chemotherapy Drug Manual 2015. Jones \& Bartlett Learning: Burlington; 2015.

11 Nair $A B$ and Jacob S: A simple practice guide for dose conversion between animals and human. J Basic Clin Pharm 7(2): 27-31, 2016. PMID: 27057123. DOI: 10.4103/09760105.177703 
12 Li Q, Shi R and Liang F: Drug sensitivity prediction with highdimensional mixture regression. PLoS One 14(2): e0212108, 2019. PMID: 30811440. DOI: 10.1371/journal.pone.0212108

13 Smirnov P, Safikhani Z, El-Hachem N, Wang D, She A, Olsen C, Freeman M, Selby H, Gendoo DM, Grossmann P, Beck AH, Aerts HJ, Lupien M, Goldenberg A and Haibe-Kains B: PharmacoGx: An R package for analysis of large pharmacogenomic datasets. Bioinformatics 32(8): 1244-1246, 2016. PMID: 26656004. DOI: 10.1093/bioinformatics/btv723

14 Cortazar P and Johnson BE: Review of the efficacy of individualized chemotherapy selected by in vitro drug sensitivity testing for patients with cancer. J Clin Oncol 17(5): 1625-1631, 1999. PMID: 10334552. DOI: 10.1200/JCO.1999.17.5.1625

15 Mekata E, Sonoda H, Shimizut T, Tatsuta T, Yamaguchi T, Endo $\mathrm{Y}$ and Tani T: Clinical predictive value of in vitro anticancer drug sensitivity test for the therapeutic effect of adjuvant chemotherapy in patients with stage II-III colorectal cancer. Mol Clin Oncol 1(4): 763-767, 2013. PMID: 24649243. DOI: $10.3892 / \mathrm{mco} .2013 .102$

16 Cancer Cell Line Encyclopedia Consortium and Genomics of Drug Sensitivity in Cancer: Pharmacogenomic agreement between two cancer cell line data sets. Nature 528(7580): 84-87, 2015. PMID: 26570998. DOI: 10.1038/nature15736
17 Roscilli G, De Vitis C, Ferrara FF, Noto A, Cherubini E, Ricci A, Mariotta S, Giarnieri E, Giovagnoli MR, Torrisi MR, Bergantino F, Costantini S, Fenizia F, Lambiase M, Aurisicchio L, Normanno N, Ciliberto G and Mancini R: Human lung adenocarcinoma cell cultures derived from malignant pleural effusions as model system to predict patients chemosensitivity. J Transl Med 14: 61, 2016. PMID: 26928703. DOI: 10.1186/s12967-016-0816-x

18 Ben-David U, Ha G, Tseng YY, Greenwald NF, Oh C, Shih J, McFarland JM, Wong B, Boehm JS, Beroukhim R and Golub TR: Patient-derived xenografts undergo mouse-specific tumor evolution. Nat Genet 49(11): 1567-75, 2017. PMID: 28991255. DOI: $10.1038 / \mathrm{ng} .3967$

19 Mahajan AS, Sugita BM, Duttargi AN, Saenz F, Krawczyk E, McCutcheon JN, Fonseca AS, Kallakury B, Pohlmann P, Gusev $\mathrm{Y}$ and Cavalli LR: Genomic comparison of early-passage conditionally reprogrammed breast cancer cells to their corresponding primary tumors. PLoS One 12(10): e0186190, 2017. PMID: 29049316. DOI: 10.1371/journal.pone.0186190

Received November 6, 2019

Revised November 14, 2019

Accepted November 18, 2019 